\title{
The design of rate of return guarantees for defined contribution plans
}

Received: 17th April, 2001

\section{John Turner}

is a senior policy adviser at AARP. He has published numerious articles and more than a dozen books on public policy relating to pensions and social security old age benefits. He has a PhD in Economics from the University of Chicago.

\begin{abstract}
While the financial market risks are borne by the plan sponsor for defined benefit plans, in most defined contribution plans those risks are borne entirely by workers. Some analysts argue that, as primary plans, defined contribution plans place too much financial market risk on workers. ${ }^{1}$ Recognising the need to limit their risks to workers, mandatory defined contribution systems, which are found primarily in Latin America, generally provide some form of rate of return or minimum benefit guarantee. ${ }^{2}$ A number of voluntary defined contribution plans around the world also provide rate of return guarantees. ${ }^{3}$

For employers considering offering a rate of return guarantee this paper explores the conceptual basis for an employer-backed minimum rate of return guarantee. It does so by analysing different possible features of rate of return guarantees. In considering possible features, the analysis is not limited to guarantee features that currently would be allowed for ERISA plans in the USA, but rather considers the full range of possible features. Extending earlier analyses, ${ }^{4}$ it applies this framework to model a $401(\mathrm{k})$ type plan where the employer match contribution depends on the rate of return earned on the plan assets.
\end{abstract}

This paper indicates that employers considering offering a guarantee need to consider four issues:

- the measurement of the rate of return to be guaranteed

- the process determining the guarantee

- the insurance provided by the guarantee

- the financial backing for the guarantee.

Keywords: defined contribution plans; rate of return; guarantees

John Turner

Centre for Pensions and Social Insurance, 3713

Chesapeake St. NW,

Washington, DC 20016, USA.

e-mail: jturner@aarp.org

\section{Rate of return guarantees}

During the period of work and contributions before retirement, pension guarantees can provide either a minimum level of benefits at retirement or a minimum rate of return. Minimum benefit guarantees can be structured so that they are antipoverty benefits that only affect low income workers, with a flat guarantee for all workers.

Alternatively, they can be structured so that the guarantee is different for each 
worker, depending on how much is contributed to the worker's pension account. Guarantees during retirement can involve protection of the real level of benefits against inflation and protection against the risk of outliving benefits. This paper focuses on minimum rate of return guarantees during the accumulation phase.

To better understand how they work, this section takes a detailed look at the structure of rate of return guarantees for defined contribution plans. There are at least 20 different aspects of rate of return guarantees, with the various combinations of features resulting in many different types of guarantees. The aspects of rate of return guarantees considered are divided into four areas: the measurement of the rate of return that is guaranteed; the process by which the guarantee is determined; the risk and expected return characteristics of the guarantee; and the financing of the guarantee. Understanding these different aspects of rate of return guarantees is important both for analysing existing guarantees and for designing new guarantees as part of a pension or social security reform.

\section{Measurement of the guaranteed rate of return}

The rate of return to be guaranteed can be measured different ways.

Real or nominal. The guaranteed rate of return can be a real rate of return or a fixed nominal rate of return or a hybrid. The guarantee of a real rate of return and the guarantee of a nominal rate of return are two extremes. A guarantee could be structured so that the guaranteed rate of return fell between the two. This type of guarantee is implicitly provided when a COLA (cost of living adjustment) is set at the inflation rate less a fixed percent.
Uruguay uses a real rate of return guarantee on its individual account plans, while Switzerland uses a nominal rate of return guarantee.

Fixed or indexed. The guarantee can be a fixed rate of return (either nominal or real), or it can be a rate of return that varies according to a capital market index. The index could be based on the rate of return received on a given asset or portfolio of assets, on the actuarial rate of return assumed for an associated defined benefit plan, or the rate of return received by a given group of investors, such as all pension fund managers. The state defined contribution plan for teachers in Indiana offers a guarantee based on the actuarial rate of return assumed on the associated defined benefit plan. Uruguay uses a fixed rate of return guarantee, while Chile uses one that varies according to an index. Pennacchi ${ }^{5}$ has analyzed the guarantees used in Uruguay and Chile, while Lindset ${ }^{6}$ analyses guarantees more generically.

The averaging period for the guaranteed rate of return. The time dimension on the rate of return can be for a fixed period, such as the rate of return over a month, a calendar year or each consecutive 12 month period; or it can be a cumulative rate of return based on compounding annual rates of return over a longer period. Some plans for government workers in New Zealand use a cumulative rate of return. Chile until 1999 used an annual rate of return over each consecutive 12 month period; now it is for 36 month periods. Most guarantees use annual periods as the guarantee period. When a longer time period is used, the cost of providing the guarantee is reduced because returns averaged over longer periods are less likely to fall below the guaranteed level.

Explicit or implicit rates of return. A rate of return guarantee is equivalent to a guarantee of a minimum level of assets in 
the worker's pension account, given the contributions. Thus, a guarantee of a minimum level of the pension fund implicitly guarantees a minimum rate of return. Alternatively, the rate of return guarantee may be a guarantee of an explicitly stated rate. Chile uses a guarantee based on explicit rates of return, while the guarantee on mandatory individual accounts in Mexico has an implicit rate of return, that being the rate of return that would be sufficient to provide the guaranteed minimum benefit.

The actual rate of return received on the portfolio or a benchmark rate of return. The guaranteed rate of return may be the actual rate of return received on the pension portfolio or it may be a benchmark rate of return; the latter would eliminate the problem of moral hazard in the selection of investment portfolios by workers, employers or pension fund managers, and would allow a wider range of portfolios to be selected. With moral hazard, if workers managed their pension portfolios but the employer or pension fund company provided the guarantee, the workers would have the incentive to invest in very risky assets if the guarantee was based on the actual portfolio returns. Chile uses the actual rate of return received, while Feldstein et al. propose a guarantee based on a benchmark. ${ }^{7}$

Gross or net rates of return. The guaranteed rate of return can be gross or net of expenses. A similar type of measurement issue is that it can be calculated using the market value of assets or some other valuation.

The process determining the guarantee A mechanistic or subjective decision process. The guarantee may be based on a fixed rule versus a guarantee in which the guarantor has discretion. An example of a discretionary guarantee is participating life insurance, in which policy dividends are determined by a board of trustees. ${ }^{8}$ The guarantee in Chile is based on a fixed rule.

The formality of the guarantee. An explicit (formal) guarantee versus an implicit (informal) guarantee (based on expectations of political realities). The assistance provided to pensioners by the British government after the Maxwell affair in 1992 may be an example of an implicit guarantee. ${ }^{8}$ When a social security system is structured so that retirees rely heavily on a defined contribution system, they may have the expectation that if the rate of return becomes very low the government will bail them out. ${ }^{9}$ It should be a goal of public policy to make implicit guarantees explicit so that they their expected costs can be determined, and so that all affected parties will have a clear understanding of the costs.

\section{The insurance provided by the guarantee}

The guarantee can be analysed in terms of the risk and expected return the worker faces when the guarantee is in place.

The risk sharing in the guarantee. A minimum guarantee (with the possibility of the worker receiving a higher rate of return) versus a point guarantee. Guarantees differ with respect to what happens to the investment returns when the rate of return is above the guarantee level. With a point guarantee, the employer or the institution providing the guarantee receives the entire rate of return above the guarantee level when the actual rate of return exceeds the guarantee level.

With a minimum guarantee, the worker can receive the entire rate of return above the guarantee level, or the employer or the institution providing the 
guarantee may receive part of it. There may be a minimum and a maximum rate of return, so that the worker receives the entire rate of return above the minimum and below the maximum, but receives only a part of or none of the rate of return above the maximum. In Chile workers receive the entire rate of return above the minimum and below the maximum, but none of the rate of return above the maximum; that amount is deposited into a reserve account that is used to fund the rate of return guarantee. This could be considered to be a form of hedging, with the risk of a loss being reduced by reducing the potential for gain. In Poland, workers receive the entire amount above the minimum guaranteed level. In Switzerland, most mandatory plans pay exactly the fixed guaranteed rate of return of 4 per cent nominal, regardless of whether the actual portfolio return is above or below that rate.

The application frequency of the guarantee. The guarantee period determines the point in time at which the guarantee is exercised. It can be a fixed periodic interval, such as a quarter or a year, so that it is a series of successive guarantees; or it can be a cumulative guarantee, so that the guarantee period is from the start of participation until the end of participation, and the guarantee is based on the termination value of the account. For an example to distinguish between the averaging period of the rate of return and the application frequency of the guarantee, a cumulative guarantee can provide that the cumulated rate exceed a minimum cumulated rate at the end of every year, or only at the end of participation in the plan. The application frequency will normally be greater or equal to the averaging period.

The extent of liability of the party (the guarantor) making the guarantee. The guarantor can have limited liability or unlimited liability. When the guarantor has limited liability, the guarantee provides that there is a cap on the expenditure the guarantor is required to make. This is analogous to caps in health insurance policies.

The risk that the guarantor will fail to meet the guarantee. The guarantee can have a near 100 per cent certainty versus a guarantee with some residual uncertainty as to whether the guaranteed rate of return would be fully met. In reality, all guarantees have some degree of risk that financial catastrophe would occur and they would not be met.

The risk that the guarantee will be prospectively changed. The guarantee may be viewed as an enduring promise, or as a promise that is likely to be revised in the future. All guarantees have some risk that the guarantee will be revised prospectively at some point in the future.

The type of insurance provided. A guarantee that is set fairly high relative to the expected return, versus a guarantee that only provides catastrophic protection against a low rate of return. Guarantees can be characterised by the expected value of the percentage of the years that the guarantee will be exercised. For example, guarantees can be characterised as 20 per cent, 50 per cent, or 80 per cent guarantees, having the expectation that in that percentage of years the guarantee will be called upon.

An individual participant based guarantee or a plan based guarantee. When a guarantee is a fixed periodic guarantee and a number of workers participate in the same defined contribution plan, the guarantee can be provided on a plan basis. When each individual has a different investment portfolio, the guarantee is provided on an individual basis. Cumulative guarantees generally must be determined on an individual basis, but under special circumstances (when all members of a plan have the 
same start date and the guarantee is settled every year) a plan-wide guarantee may be used. The guarantee in Chile is done on a plan basis, while some plans in New Zealand with a cumulative guarantee provide the guarantee on an individual basis.

The degree of choice the worker has associated with the guarantee. The guarantee can be mandatory or voluntary. The mandatory or voluntary aspect of it can differ for employers and employees. For example, it could be voluntary for employers, but employers could make it mandatory for their employees.

Alternatively, it could be mandatory that employers offering a defined contribution plan offer a guarantee as an option, but it would be voluntary for employers to choose that option. In either case voluntary or mandatory - the worker could be provided a choice of different guarantees, with varying combinations of expected return and level of guaranteed rate of return. In Norway, Parliament proposed, but subsequently rejected, a guarantee that would be voluntary for employers in that they would not be required to provide such a plan, but would be mandatory for workers at firms that choose it.

\section{The financial backing for the guarantee}

Funded or pay-as-you-go. Guarantees can be fully or partially advanced funded, or they can be financed on a pay-as-you-go basis. The guarantee on mandatory defined contribution plans in Chile is partially advanced funded, with the government having a residual liability on a pay-as-you-go basis if the private sector funding for guarantees is insufficient.

The party financing the guarantee. A guarantee can be financed by the employee, the employer, the pension fund management firm, or the government. In Chile, the guarantee is partially financed by the employee, in that in some periods part of the rate of return received on his account is set aside to finance the guarantee. It is partially financed by the pension fund management company, which must set aside some of its own money to finance the guarantee. It is also partially financed by the government, which is the insurer of last resort.

The party backing the guarantee. The party backing the guarantee, which is not necessarily the same as the party financing the guarantee, can be an employer, a pension fund provider, an insurance company, or the government. Jefferson proposes a rate of return guarantee financed by employer premiums paid to the Pension Benefit Guaranty Corporation. ${ }^{10}$

Purchase of a guaranteed product or purchase of a guarantee. The guarantee can be obtained by purchasing a guaranteed product, such as from an insurance company, or the guarantee can be provided on a portfolio that would otherwise not be guaranteed.

Defined contribution plans in the USA have at least three ways to provide a guaranteed rate of return to participants. First, participants or plan sponsors may purchase GICs (Guaranteed Income Contracts) or fixed annuity contracts from insurance companies. The insurance company guarantees the nominal rate of return. Secondly, they may invest in inflation indexed bonds, which provide a guaranteed real rate of return, or in traditional government bonds, where the government in essence guarantees a nominal rate of return. Thirdly, they may buy a put option to guarantee a minimum price on the stocks and bonds in their portfolio. With a put option, they buy the right to sell stocks or bonds at a fixed minimum price, setting a floor on the value of their portfolio. 
Table 1: Analysis of the rate of return guarantee for a 401(k)-type plan based on employer contribution

\begin{tabular}{ll}
\hline Criteria & Plan feature \\
\hline Measurement of guaranteed rate of return & Nominal \\
1. Real or nominal & Fixed \\
2. Fixed or indexed & 1 year \\
3. Averaging period & Explicit \\
4. Explicit or implicit & Actual \\
5. Actual or benchmark & Net \\
6. Gross or net & \\
Process determining guarantee & Mechanistic \\
1. Mechanistic or subjective & Explicit \\
2. Explicit or implicit guarantee & \\
Guarantee & Participating \\
1. Point or participating & 1 year \\
2. Application frequency & Limited \\
3. Full or limited liability & Subjective, depending on employer \\
4. Risk of failure of guarantee & Subjective, depending on employer \\
5. Risk of change of guarantee & Normal \\
6. Catastrophic or normal insurance & Individual \\
7. Individual or plan based & Voluntary \\
8. Mandatory or voluntary & \\
Financial backing & Pay-as-you go \\
1. Funded or pay-as-you-go & Employer \\
2. Party financing & Employer \\
3. Party backing guarantee & Guarantee \\
4. Guaranteed product or guarantee &
\end{tabular}

Source: Author.

\section{A minimum rate of return guarantee}

This section applies this framework to analyse a possible guarantee option for 401(k) plans. Table 1 summarises the guarantee presented here using this framework. The guarantee discussed here is provided directly by the employer. Using the analytical framework just described, the guarantee is an explicit guarantee on an individual participant basis of a fixed minimum nominal annual rate of return with the employer having limited liability.

A common feature among 401(k) plans and similar defined contribution plans is an employer match for employee contributions. This feature is found, for example, in the Thrift Savings Plan for federal government employees. With a match, the employer will contribute an amount, typically between $\$ 0.50$ and $\$ 1$ for each dollar that the employee contributes, up to a ceiling percentage of salary. The guarantee proposed here uses an employer match for employee contributions, but the match is only provided when the rate of return is below the guarantee level.

The guaranteed defined contribution plan considered here has three design parameters. To illustrate how the guarantee works, a prototype plan is presented. The prototype plan would have individual accounts in which the worker's contribution $C$ equals 2 per cent of the worker's pay $P$ (parameter 1, the base contribution rate).

$$
C=0.02 P
$$

It would guarantee a minimum annual nominal rate of return $g$ of 6 per cent (parameter 2, the guaranteed rate of return).

$$
g=0.06
$$

The plan sponsor would back the guarantee by a supplemental annual 
contribution $S$ of up to 2 per cent of the worker's pay (parameter 3 , the maximum supplementary contribution).

$$
S \leq 0.02 P
$$

The plan sponsor can vary the numerical values of these parameters to make the contribution rate higher or lower (parameter 1), to make the guarantee more or less generous (parameter 2), and to make the guarantee more or less secure (parameter 3 ).

If the plan earned a rate of return of 6 per cent or more, the rate of return $r$ that the participant received would equal the actual rate of return $\mathrm{p}$ received on the portfolio.

$$
r=p, \text { if } r \geq g
$$

If the plan in a year earned less than the 6 per cent guaranteed rate of return, the plan sponsor would contribute a supplementary matching amount, up to 2 per cent of pay per worker, to raise the worker's account balance to where it would have been had the plan earned a 6 per cent rate of return that year.

$$
\begin{aligned}
A(t)= & A(t-1) r(t-1)+C(t)+S(t), \\
& \text { if } r(t)<g,
\end{aligned}
$$

where

$$
\begin{aligned}
S(t)= & (g-r(t-1)) A(t-1), \\
& \text { subject to inequality }
\end{aligned}
$$

If the contribution of an additional 2 percent of pay were insufficient to raise the rate of return to the guaranteed minimum, the guaranteed minimum would not be met in that year, but no liability to the plan sponsor would be carried over to the following plan year.

This guaranteed form of $401(\mathrm{k})$ plan differs from the traditional $401(\mathrm{k})$ plan with employer matching contribution, in that the employer match depends on the rate of return received by the plan, rather than being based on the amount the employee contributes.

Generally, forms of investment protection generate the problem of moral hazard. ${ }^{11}$ Once the losses from a risk are insured, people will take less care to avoid that risk happening. Specifically, in this case they would be encouraged to invest in riskier portfolios than they otherwise would do.

If it were thought that the problem of moral hazard would cause participants to make investments that were excessively risky, the plan sponsor would need to choose the investment portfolio to control the risk that the plan sponsor is guaranteeing. The guarantee described here would not be subject to moral hazard problems since the employer rather than the employee would direct the investments of the pension. Employers would presumably invest in a mixed stock-bond portfolio to assure that in most years they did not need to make additional payments to meet the guaranteed minimum rate of return.

While it may appear that the employer bears the cost of providing the guarantee, in actuality the employee ultimately bears the cost of the guarantee through two adjustments by the employer. First, the employer will presumably invest in a more conservative portfolio, so the employee bears the cost of a reduced expected rate of return. Secondly, labour market theory suggests that the employer would reduce other forms of compensation to employees if its costs of providing a pension benefit are increased.

This type of guarantee is similar to the employer writing a put option on the average return in the underlying assets in the fund. ${ }^{12}$ A put option allows the holder (the participant) to 'sell' the underlying asset (the pension fund) at a 
set price (the amount determined by the guaranteed rate of return at a set date). In effect, the guaranteed minimum rate of return is equivalent to a guaranteed minimum value of the portfolio at the end of the guarantee period.

This type of guarantee addresses the criticism that some cohorts may be lucky and some unlucky with respect to the rates of return they receive. This type of guarantee, by providing a fixed minimum guaranteed rate of return, provides a certain amount of smoothing of rates of return over time.

\section{Variations}

The discussion of the different dimensions of rate of return guarantees indicates that there are numerous possible variations on the prototype guarantee discussed here. This section highlights a few of the alternatives. An alternative type of guarantee would be more like a catastrophic guarantee. A prototype plan for that type of coverage could be a guarantee of a 1 per cent rate of return, but with a supplementary contribution of 3 per cent of pay. With this alternative, employers would presumably maintain a conservative investment portfolio. A large employer could offer a range of options that were equivalent in expected cost but varied in risk to the employee. This could be done by matching a lower guaranteed rate of return with a higher maximum supplementary contribution. This type of guarantee would expand the range of choices open to workers.

Instead of having the employer make the base contribution, part or all of the base contribution could be made by the employee.

Besides varying the values of the three parameters of the plan, other variations are worth considering. The guarantee could be backed by a supplementary contribution determined as a maximum percentage of the account balance rather than a percentage of the worker's earnings. This type of guarantee would provide greater security to workers with large account balances, who would tend to be highly compensated and long-tenure workers. The security of the guarantee could be increased by carrying forward a liability in years when the supplementary contribution was insufficient to raise the rate of return received to the guaranteed minimum. That feature would increase both the expense and the administrative complexity of the guarantee.

The guarantee could be structured so that it worked more like a rebate to the employer in high rate of return years. Under this type of guarantee, the employer would contribute 2 per cent every year except years when the rate of return exceeded a fixed level, say 8 per cent. It could be phased in so that the employer contributed 1 per cent when the rate of return exceeded 7 per cent, and made no contribution when it exceeded 8 per cent.

As well as through pay-as-you-go funding, there are at least two ways the guarantee could be financed on a prefunded or partially prefunded basis, given a legal environment enabling them. First, it could be financed by an annual payment similar to an insurance premium. The premium payments would be set aside in a reserve fund. Secondly, it could be financed out of the investment income. The guarantee could be financed by the employer receiving part or all of the rate of return above the guaranteed level, a feature that would not be allowed under current pension law in the USA, but that was a feature of proposed legislation in Norway. Alternatively, it could be financed through part or all of the investment income above a set level being set aside in a reserve fund, as is done in Chile. 


\section{Conclusions}

Guaranteed defined contribution schemes can provide a low risk, low cost retirement plan or option that may appeal to some workers and employers. They are a feature of a number of mandatory as well as voluntary defined contribution plan around the world. This paper has analysed the structure of rate of return guarantees. It presents a guarantee that can be viewed as a modification of the traditional $401(\mathrm{k})$ plan with employer match, and discussed variants on this guarantee using the framework presented.

\section{Acknowledgment}

I have received valuable comments from David McCarthy, David Rajnes and participants at seminars at the Social Security Administration, the Bureau of Labor Statistics and AARP. The opinions expressed here are the author's own and do not represent the position of AARP.

\section{References}

1 Ferguson, K. and Blackwell, K. (1995) Pensions in Crisis: Why the System is Failing America and How You Can Protect Your Future, Arcade Press.

2 See, for example, Gillion, C., Turner, J., Bailey, C. and Latulippe, D. (eds.), Social Security Pensions: Development and Reform, Switzerland, International Labour Office, 2000, and Turner, J. and Rajnes, D. (2001a) 'Rate of Return Guarantees for Mandatory Defined Contribution Plans', International Social Security Review, forthcoming.

3 Turner, J. and Rajnes, D. (2001b) Rate of Return Guarantees for Voluntary Defined Contribution Plans, Unpublished manuscript.

4 Turner, J. (2000) 'Guaranteed Defined Contribution Plans', Contingencies, pp. 77-80, July/August, and Turner, J. (2001) 'Rate-of-Return Guarantees for Defined Contribution Plans', Benefits Quarterly, First Quarter, pp. 46-53.

5 Pennacchi, G. G. (1999) 'The Value of Guarantees on Pension Fund Returns', Journal of Risk and Insurance, 66, pp. 219-237, June.

6 Lindset, S. (2001) 'Defined Contribution and Defined Benefit Pension Plans with Guarantees', Unpublished paper, 6th March.

7 Feldstein, M., Ranguelova, E. and Samwick, A. 'The Transition to Investment-Based Social Security when Portfolio Returns and Capital Profitability are Uncertain', National Bureau of Economic Research (NBER) Working Paper 7016, March 1999.

8 Valdes-Prieto, S. (1998) Risks in Pensions and Annuities: Efficient Designs, Human Development Network, Social Protection Paper No. 9804, The World Bank, February.

9 Miles, D. and Timmermann, A. (1999) 'Risk Sharing and Transition Costs in the Reform of Pension Systems in Europe', Economic Policy, 29, pp. 253-286.

10 Jefferson, R. T. (2000) 'Rethinking the Risk of Defined Contribution Plans', Tax Notes 9, 28th August 28, pp. 1171-1172.

11 Whitehouse, E. (2000) 'Guarantees: Cost and Repercussions of Guaranteeing Funded Pension Benefits', AXIA Viewpoint, downloaded 18th January from www.axiaecon.com.

12 See 11 above. 